\title{
Planejamento de cardápios para escolas públicas municipais: reflexão e ilustração desse processo em duas capitais brasileiras ${ }^{1}$
}

\section{$(1$}

Planning menus for municipal schools: discussion and illustration of this process in two

Brazilian state capitals

Cristine Garcia GABRIEL²

Larissa da Cunha Feio COSTA ${ }^{3}$

Maria Cristina Marino CALVO2

Francisco de Assis Guedes de VASCONCELOS ${ }^{4}$

RE S U M O

\section{Objetivos}

Refletir sobre o planejamento dos cardápios do Programa Nacional de Alimentação Escolar, e apresentar o procedimento em Florianópolis (SC) e Belém (PA).

\section{Métodos}

Estudo transversal realizado por entrevistas com nutricionistas do Programa Nacional de Alimentação Escolar e análise de cardápios de 2010 da rede municipal de ensino fundamental. Utilizou-se como referência a Resolução n³8/2009, expedida pelo gestor federal do programa.

\section{Resultados}

Em Belém, encontraram-se cardápios padronizados para as escolas e baixa oferta de frutas/hortaliças; em Florianópolis, cardápios elaborados segundo critérios da gestão, conforme as particularidades das escolas, com maior oferta de frutas/hortaliças. Nas duas capitais, a utilização de alimentos regionais mostrou-se pequena, com ausência de compra direta de agricultores familiares.

\footnotetext{
1 Apoio Conselho Nacional de Desenvolvimento Científico e Tecnológico (CNPq) (Processo no 559328/2010-9/Edital MCT-SECIS/CNPq no 019/2010).

2 Universidade Federal de Santa Catarina, Centro de Ciências da Saúde, Departamento de Saúde Pública, Programa de Pós-Graduação em Saúde Coletiva. Campus Universitário, Trindade, 88040-970, Florianópolis, SC, Brasil. Correspondência para/Correspondence to: CG GABRIEL.E-mail: <cris_ntr@hotmail.com>.

3 Universidade Federal de Santa Catarina, Centro de Ciências da Saúde, Núcleo de Extensão e Pesquisa em Avaliação em Saúde. Florianópolis, SC, Brasil.

${ }^{4}$ Universidade Federal de Santa Catarina, Centro de Ciências da Saúde, Programa de Pós-Graduação em Nutrição. Florianópolis, SC, Brasil.
} 


\section{Conclusão}

Observaram-se muitas peculiaridades nas capitais, refletindo a diversidade na execução do programa após a municipalização. Apontam-se a necessidade de maior inclusão de alimentos regionais nos cardápios e a efetivação de instrumentos legais que viabilizem a entrada dos pequenos produtores locais no mercado.

Termos de indexação: Alimentação escolar. Planejamento de cardápio. Programas e políticas de nutrição e alimentação.

\section{A B S T R A C T}

\section{Objective}

The aim of the present study was to reflect on the planning of menus for the Brazilian National School Food Program, illustrating this procedure in the cities of Florianópolis (SC) and Belém (PA).

\section{Methods}

A cross-sectional study was done to interview program dieticians and analyze the menus of 2010 for municipal elementary schools. The resolution $n^{\circ}$ 38/2009 passed by the federal program manager was used as reference.

\section{Results}

The menus in Belém were standardized and contained little produce. In Florianópolis, the menus were prepared according to management criteria and particularities of the schools, and contained more produce. In both capital cities, regional foods were used infrequently and food was never purchased directly from producers.

\section{Conclusion}

Various peculiarities were found in the study capitals, demonstrating a nonstandard implementation of the National School Food Program after its decentralization. The program needs to include more regional foods in the menu and laws that encourage direct purchasing from local producers.

Indexing terms: School feeding. Menu planning. Nutrition programs and policies.

\section{N T R O D U ÇÃ O}

O Programa Nacional de Alimentação Escolar (PNAE) é um dos maiores programas de alimentação escolar do mundo, sendo considerado o mais antigo do Brasil na área de Segurança Alimentar e Nutricional (SAN) ${ }^{1,2}$. Um fato marcante em sua trajetória é a descentralização dos recursos para sua execução a partir de 1994. Anteriormente a esse período, era o órgão gestor federal que realizava o planejamento dos cardápios utilizados de forma padronizada em todo território nacional ${ }^{1,3,4}$.

O PNAE é gerenciado pelo Fundo Nacional de Desenvolvimento da Educação (FNDE) do Ministério da Educação, e, em 2009, a legislação do Programa avançou em pontos importantes, estabelecendo como objetivo:

contribuir para o crescimento e o desenvolvimento biopsicossocial, a aprendiza- gem, o rendimento escolar e a formação de hábitos alimentares saudáveis dos alunos de toda a educação básica pública, por meio de ações de educação alimentar e nutricional e da oferta de refeições que cubram as suas necessidades nutricionais durante o período letivo (Art. $\left.4^{\circ}\right)^{5}$.

Nessa perspectiva, os cardápios do PNAE são considerados importante instrumento para satisfação das necessidades nutricionais e formação de hábitos alimentares saudáveis ${ }^{6-11}$, devendo contribuir para a promoção da saúde e também para a preservação da cultura alimen$\operatorname{tar}^{12,13}$. Assim, destaca-se que o adequado planejamento e o acompanhamento da execução dos cardápios são essenciais para o alcance dos objetivos do programa7,8,13.

Embora a trajetória de existência do PNAE seja longa, ainda são escassos os estudos que exploram a potencialidade do programa como 
promotor de hábitos alimentares saudáveis e/ou também regionais ${ }^{12,14}$, bem como são raros os estudos que envolvem especificamente seus cardápios.

Pesquisa realizada em 2005 com 41 merendeiras de João Pessoa (PB) atentou para o fato de que a participação dessas no processo de elaboração dos cardápios foi significativa, apontando, concomitantemente, que o envolvimento do nutricionista estava limitado a observar a variedade das preparações ${ }^{15}$. Embora a participação das merendeiras e demais profissionais da comunidade escolar seja importante na escolha de preparações que compõem o cardápio, salienta-se que o planejamento do cardápio é uma atividade inerente ao nutricionista ${ }^{5,6,15}$.

Belik \& Chaim² evidenciaram que a qualidade nutricional na execução do PNAE foi um dos pontos fortes das prefeituras vencedoras do Prêmio Gestor Eficiente da Merenda Escolar, entre os anos de 2004 e 2005. Para avaliar a adequação do cardápio, os nutricionistas referiram realizar o acompanhamento nutricional dos beneficiários; algumas prefeituras iam além, produzindo cardápios para crianças celíacas e diabéticas e/ou adotando alimentos orgânicos na alimentação².

Estudo conduzido por Chaves et al..$^{12}$ analisou a utilização de preparações regionais nos cardápios elaborados em 2007 para a alimentação escolar do ensino público brasileiro e destacou a Região Sul do País, já que $86 \%$ dos cardápios contemplavam pelo menos uma preparação regional por semana, enquanto na Região Norte esse percentual caía para 38\%. Dentre os cardápios analisados nas regiões geográficas, $63 \%$ a $88 \%$ foram elaborados por nutricionistas; desses, poucos contemplavam preparações regionais, o que indica que o respeito à cultura alimentar estava aquém do idealizado pelo programa ${ }^{5,6,12,16}$.

Domene et al. ${ }^{17}$ enfatizam que existem ainda poucos dados que avaliam os cardápios do PNAE do ponto de vista nutricional. Ao estudarem as preparações oferecidas pelo programa em Campinas (SP), observaram que elas não atendiam rigorosamente a previsão quantitativa de nutrientes, o que reforça a importância de que as refeições sejam previamente submetidas a comparações com as recomendações nutricionais.

Dada a amplitude de sua cobertura populacional, sabe-se que o PNAE tem peculiaridades inerentes a cada modalidade de ensino atendida e a cada região do Brasil'12,14. Dessa forma, este artigo tem como propósito discutir e ilustrar o processo de planejamento de cardápios para o ensino fundamental do PNAE em escolas públicas municipais em duas capitais brasileiras: Florianópolis (SC) e Belém (PA).

\section{MÉ TO D O S}

Estudo descritivo de delineamento transversal, com coleta de dados realizada de outubro a novembro de 2010, conduzido em duas capitais brasileiras: Florianópolis e Belém. A seleção das capitais ocorreu por conveniência e acesso às informações.

Para a coleta de dados, estruturou-se um roteiro com questões abertas sobre o funcionamento do PNAE, que foi aplicado aos responsáveis pela gestão do programa nas capitais. Em Belém, a Fundação Municipal de Assistência ao Estudante (FMAE) gerencia o programa; em Florianópolis, esse papel é desempenhado pelo Departamento de Alimentação Escolar (DEPAE). As duas instituições são vinculadas às Secretarias Municipais de Educação.

Previamente à coleta de dados, os pesquisadores realizaram contato com os órgãos gestores supracitados, explicitando os objetivos da pesquisa, e agendando a coleta de dados, preferencialmente com um nutricionista envolvido na gestão do programa. Em Florianópolis, as respondentes das questões foram duas nutricionistas, ambas ligadas ao DEPAE, sendo uma a Responsável Técnica (RT) pelo PNAE. Já em Belém, a entrevistada foi a nutricionista RT pela alimentação escolar, que também ocupava o cargo de coordenadora da Divisão de Controle e Avaliação da FMAE. 
A coleta de dados foi realizada por duas nutricionistas pesquisadoras ligadas ao Núcleo de Extensão e Pesquisa em Avaliação em Saúde (NEPAS/Departamento de Saúde Pública da Universidade Federal de Santa Catarina).

As variáveis investigadas foram: modalidade de gestão do PNAE; modalidades de ensino atendidas; contrapartida do município com relação à aquisição de alimentos, quando existente; processo de elaboração dos cardápios; existência de critérios para a elaboração dos cardápios ou existência de cardápios padrão, geral ou por modalidade de ensino; número de nutricionistas atuando na alimentação escolar, conforme vínculo de trabalho; número de instituições de ensino sob responsabilidade do(s) nutricionista(s); possibilidade e autonomia das instituições de ensino para modificarem/adaptarem os cardápios; adequação qualitativa e quantitativa dos cardápios aos parâmetros estabelecidos pela legislação e processo de escolha dos fornecedores.

Ao final das entrevistas, foram solicitados os cardápios oferecidos nas escolas do ensino fundamental no ano de 2010, além da pauta de compra dos alimentos, visando a uma análise qualitativa. Os valores da contrapartida municipal com as despesas não alimentícias (infraestrutura das cozinhas, contratação de pessoal, água, luz, dentre outras) não foram solicitados, não constituindo objetos do estudo.

Os itens normativos em vigor que orientam o planejamento de cardápios para a alimentação escolar estão dispostos na Resolução n 38/2009 do FNDE ${ }^{6}$. Para avaliação dos dados, utilizaram-se como referência os parâmetros estabelecidos nos artigos 15, 16, 17 e 18 dessa Resolução ${ }^{6}$. Esses artigos dispõem que os cardápios devem ser elaborados por nutricionista, respeitando-se as referências nutricionais (segundo faixa etária e a presença de escolares com necessidade de atenção específica), os hábitos e a cultura alimentar da localidade, pautando-se na sustentabilidade e diversificação agrícola da região e na alimentação saudável e adequada. Para isso, a Resolução ${ }^{6}$ estabelece percentuais médios de suprimento das necessidades nutricionais diárias dos alunos; a quantidade mínima de frutas e hortaliças por semana (três porções ou 200g/aluno/semana); os alimentos de aquisição proibida (bebidas com baixo teor nutricional) e restrita (como enlatados, embutidos e doces) com os recursos do FNDE e dispõe que no mínimo 30\% do total dos recursos repassados pelo FNDE deverão ser utilizados na aquisição de alimentos diretamente da agricultura familiar e do empreendedor familiar rural ou suas organizações ${ }^{6}$.

Realizou-se análise exploratória das variáveis investigadas e, com base nos parâmetros da Resolução/FNDE n 38/20096, analisaram-se os cardápios do ensino fundamental disponibilizados para verificar se foram planejados por nutricionistas e se respeitavam as referências nutricionais. Os cardápios foram ainda avaliados segundo a presença ou ausência de alimentos proibidos pela normativa, alimentos regionais e pela oferta de frutas e hortaliças. Foi verificado também se a gestão municipal do programa realizou em 2010 a aquisição de gêneros alimentícios diretamente da agricultura familiar e do empreendedor familiar rural ou suas organizações. Não foi estudado neste artigo o quantitativo financeiro empregado para os alimentos restritos pela legislação.

Os alimentos e preparações regionais foram considerados segundo a lista de alimentos regionais do Ministério da Saúde ${ }^{18}$ e a Tabela de Alimentos de Aguiar $^{19}$, específica para a região amazônica.

O presente artigo faz parte de uma pesquisa de maior extensão (Edital MCT-SECIS/CNPq $n^{\circ}$ 019/2010 - processo $n^{\circ}$ 559328/2010-9), que foi aprovada pelo Comitê de Ética em Pesquisa da Universidade Federal de Santa Catarina (processo $n^{\circ} 1143$ de 29/11/10). Os participantes assinaram um termo de consentimento livre e esclarecido. 


\section{RESULTADOS}

Os dados do Censo Educacional do Ministério da Educação de 2010 apresentam Belém com 71,2 mil alunos matriculados na rede municipal de ensino, e Florianópolis com 26,5 mil20 (Tabela 1). No mesmo ano, as duas capitais adotavam a modalidade de execução centralizada, concentrando a administração dos recursos e compras dos gêneros, embora em Florianópolis houvesse terceirização da mão de obra para o PNAE.

A contrapartida do município na aquisição de alimentos para o PNAE em Belém era somente para as creches, que supriam $92 \%$ do valor da alimentação, equivalente a $R \$ 2,84$ por aluno por dia (valor destinado somente à compra de alimentos). Florianópolis alocava recursos financeiros próprios em todas as modalidades de ensino cobertas pelo programa, o que correspondia a $78 \%$ dos custos da alimentação nas creches; a $74 \%$ na pré-escola; a $65 \%$ no ensino fundamental; a $71 \%$ para estudantes do Programa Mais Educação; e a $63 \%$ para alunos da Educação de Jovens e Adultos (EJA).

\section{Planejamento de cardápios}

Ao investigar "sobre quem planeja a alimentação", observou-se que nas duas capitais havia equipe de nutricionistas. Em Belém, a equipe de Coordenação de Divisão de Controle e Avaliação da FMAE estava composta por três nutricionistas efetivos, responsáveis pela alimentação das 216 unidades de ensino do município, com atribuições técnicas e administrativas. Nas 128 unidades municipais de Florianópolis, eram três nutricionistas efetivas alocadas no DEPAE, e mais nove nutricionistas contratadas por empresa terceirizada. As três profissionais com vínculo efetivo atuavam na gestão da alimentação escolar, oito contratadas faziam a supervisão nas instituições de ensino, com média de 15 escolas para cada uma, e uma fazia a coordenação.

Para as RT entrevistadas, o critério para o planejamento dos cardápios nas duas capitais seguia as atuais normativas do PNAE ${ }^{5,6}$. No caso de Belém, era elaborado um cardápio padrão para todas as unidades de ensino, com indicação do número de vezes que os alimentos ou preparações seriam repetidos em cada mês. Os fatores que influenciavam esse planejamento estavam relacionados às preparações diferenciadas para a pré-escola, ao período de atividade escolar - parcial ou integral, ao número de cozinheiras, e à capacidade de armazenamento das unidades de alimentação. Em Florianópolis, os critérios para elaboração dos cardápios eram constantemente atualizados, estando na época com oito modelos de cardápios, diferenciados pela modalidade de ensino e período de atendimento (parcial ou integral/número de refeições). Os modelos eram diferenciados para cada semana do mês, sendo utilizados pelas supervisoras das escolas para definição em cada realidade local e conforme a necessidade/aceitação dos escolares. A construção dos critérios para elaboração dos cardápios era responsabilidade da equipe de gestão, mas as outras nutricionistas tinham coparticipação nesse processo e discutiam os cardápios elaborados com a equipe escolar.

Tabela 1. Número de matrículas escolares nas redes municipais de Florianópolis (SC) e Belém (PA), conforme as modalidades de ensino atendidas no ano de 2010.

\begin{tabular}{lcccccc}
\hline Município* & \multicolumn{2}{c}{ Educação Infantil } & \multirow{2}{*}{ Ensino Fundamental } & Ensino Médio & Educação de Jovens e Adultos & Total \\
\cline { 2 - 3 } & Creche & Pré escola & & & & \\
\hline Florianópolis & 4841 & 5366 & 15188 & 0 & 1127 & 26522 \\
Belém & 2991 & 13484 & 45603 & 161 & 8947 & 71186 \\
\hline
\end{tabular}

Fonte: Censo Educacional do Ministério da Educação de 2010 (disponível em http://portal.inep.gov.br/basica-censo).

*Os dados englobam as matrículas nas escolas urbanas e rurais e em período parcial e integral do Ensino Regular e da Educação de Jovens e Adultos, excluindo as matrículas efetuadas na Educação Especial. 
A oferta de frutas e hortaliças apresentou comportamento diferenciado entre as duas capitais, com baixa frequência desses alimentos nos cardápios de Belém (inferior a três porções por semana), contra a presença diária de hortaliças nas refeições salgadas e de frutas como sobremesas e lanches em Florianópolis.

Dentre os alimentos proibidos pela Resolução/FNDE n 38/20096, encontrou-se, nos cardápios de Belém, o refresco artificial. Segundo relatos da entrevistada, no ano avaliado não houve produtores locais de polpas de frutas que atendessem às normativas da licitação de compras, por isso houve a utilização de refresco artificial.

Em relação à inclusão de itens regionais nos cardápios, em Belém foram encontrados: mingau de tapioca (uma vez por semana), peixe e jambu (uma vez por mês). Em Florianópolis, observaram-se farinha de mandioca (uma vez por semana), peixe e mexilhão (uma vez por semana, alternando entre um e outro). Como em Florianópolis os cardápios eram diferenciados por escola, as entrevistadas não puderam precisar a inclusão de preparações regionais.

Os valores nutricionais dos cardápios inexistiam nas duas capitais. A RT pelo programa em Belém referiu nem sempre alcançar o suprimento recomendado das necessidades diárias de nutrientes, devido ao recurso financeiro disponível. Florianópolis, por sua vez, estava iniciando um projeto para fazer os cálculos nutricionais dos cardápios na época da coleta de dados.

A aquisição direta de alimentos da agricultura familiar e/ou do empreendedor familiar rural também não foi efetuada nas capitais em 2010. Segundo as RT entrevistadas, existia uma grande dificuldade no momento da chamada pública. Em Belém, os poucos produtores existentes na região não apresentavam estrutura suficiente ou capacidade de atendimento à demanda das escolas, enquanto em Florianópolis nenhum dos produtores habilitados apresentava a docu- mentação necessária completa. O fornecimento de alimentos para o PNAE em Belém era realizado por quatro fornecedores responsáveis por sete lotes licitados, sendo dois (50\%) pertencentes ao estado do Pará e dois (50\%) de outros estados. Em Florianópolis, os fornecedores eram empresários que ganhavam o edital de compras e adquiriam os itens alimentícios de atravessadores. Dessa forma, o município não tinha controle da procedência dos produtos e as nutricionistas não sabiam informar se os gêneros eram do estado ou de fora.

\section{I S C U S S Ã O}

Os dados apresentados constituem uma representação inicial sobre o processo de elaboração dos cardápios para o ensino fundamental, abarcando dois municípios que se destacam por representarem um grande grupo de escolares matriculados em escolas públicas do Brasil. Embora este estudo englobe dois municípios com a importante característica de serem capitais de estados, pontos distintos merecem ser destacados. Em termos populacionais, Belém apresenta número de habitantes (1 351 618) bem superior à Florianópolis $\left(404\right.$ 224 ${ }^{21}$. Já com relação ao Índice de Desenvolvimento Humano Municipal (IDH-M), a capital catarinense apresenta valores superiores à capital paraense $(0,875$ e 0,806, respectivamente) ${ }^{22}$, sendo o Produto Interno Bruto (PIB) per capita de Florianópolis quase o dobro comparado ao de Belém ( $\mathrm{R} \$ 17.907,00$ e $R \$ 9.793,00$, respectivamente $)^{23}$. O Índice de Desenvolvimento da Educação Básica observado em 2009 para o ensino fundamental das escolas municipais, equivalente ao $5^{\circ}$ e $9^{\circ}$ anos, foi, respectivamente, 3,9 e 3,5 para Belém, e 5,2 e 4,5 para Florianópolis ${ }^{24}$.

O número de nutricionistas atuantes na alimentação escolar nos dois municípios está abaixo do recomendado pela Resolução n 465/2010 do Conselho Federal de Nutricionistas (CFN), que recomenda uma carga semanal mínima de 30 
horas, composta por um nutricionista RT, três nutricionistas no quadro técnico e um profissional para cada 2500 alunos; na educação infantil, a Unidade Executora deverá ter um nutricionista para cada 500 alunos $^{8}$. Em Belém, eram somente três nutricionistas atuantes para os mais de 70 mil escolares; em Florianópolis, a situação era melhor (12 nutricionistas para cerca de 27 mil escolares), mas ainda fora do parâmetro estabelecido. Um ponto satisfatório nas duas capitais foi o fato de a elaboração dos cardápios ser realizada por nutricionista: o único profissional autorizado para essa prática.

Um dos princípios do PNAE é o "compartilhamento da responsabilidade pela oferta da alimentação escolar e das ações de educação alimentar e nutricional entre os entes federados" 6 : esse ponto merece acompanhamento para garantir que os recursos sejam suficientes para cumprir os objetivos do PNAE. A contribuição financeira do município para a compra de gêneros alimentícios para o PNAE tende a contribuir para que a alimentação oferecida apresente maior variedade, qualidade e, consequentemente, maior nível de satisfação e adesão por parte dos escolares. Florianópolis contribuía financeiramente com a aquisição de alimentos para todas as modalidades de ensino, mas Belém contribuía com a aquisição de gêneros somente para a modalidade de educação infantil (creches).

Os princípios que orientam a descentralização, a fim de alcançar uma maior aproximação com os beneficiários do programa, indicam planejamento de cardápios diferenciados segundo distintas realidades. Essa diferenciação não foi observada em Belém, que apresentou cardápios padronizados para todas as unidades de ensino, além de baixa oferta de frutas e hortaliças e oferta do refresco artificial - item de aquisição proibida com os recursos do gestor federal ${ }^{6}$. Mesmo com a reconhecida dificuldade na aquisição de alimentos dos produtores locais, alternativas plausíveis precisam ser discutidas e encontradas. A realidade estrutural e econômica em Florianópolis parece ter influenciado positivamente os cardá- pios. Existiam critérios de elaboração que permitiam a descentralização da sua elaboração para os nutricionistas responsáveis pelas escolas, com presença maior que o mínimo exigido de frutas e hortaliças, e sem itens proibidos pela legislação ${ }^{6}$. Também foram observados outros pontos positivos em Florianópolis: presença de biscoitos e pães integrais e alimentação isenta de glúten para todos os alunos nas unidades de ensino onde havia celíacos, visando a um processo de inclusão.

Alcançar a meta prevista de nutrientes na alimentação escolar ainda é uma dificuldade encontrada em muitas unidades de ensino ${ }^{17,25}$. Na época do estudo, Florianópolis já havia incluído no seu plano de trabalho o cálculo dos valores nutricionais dos cardápios oferecidos, sendo este ainda um desafio para Belém. A avaliação quantitativa dos cardápios é uma etapa fundamental para assegurar que os objetivos propostos pelo PNAE sejam alcançados.

Josué de Castro, em seu clássico "Geografia da Fome", relido por Vasconcelos ${ }^{26}$, afirma que, na constituição do regime alimentar da área amazônica, onde se localiza a capital Belém, houve predominância da cultura indígena sobre as culturas dos brancos portugueses e negros africanos. A farinha de mandioca era o alimento básico da dieta, sendo consumida em diferentes preparações, misturada a alimentos oriundos da flora silvestre, da fauna aquática e terrestre, e da incipiente agricultura regional. Quanto ao extremo sul, onde se localiza a capital Florianópolis, Castro ressalta os determinantes etnoculturais que possibilitaram a diversificação e melhoria do padrão alimentar da região. Assim, as distintas etnias que migraram para a região, compostas por italianos, japoneses, alemães, poloneses, lituanos, entre outros, em muito contribuíram para a constituição do seu diversificado mosaico alimentar ${ }^{26}$.

Seguindo as tradições indígenas, em Belém é comum o uso de farinha de mandioca, açaí e demais frutas da região (maracujá, mamão, abacaxi, pupunha, cupuaçu, coco, bacuri, cupuaçu, dentre outras), além de peixes e alimentos extraídos do mangue (caranguejo, turu, caramujo, 
sururu e outros) ${ }^{27}$. Entretanto, os únicos alimentos encontrados na alimentação escolar foram a farinha de tapioca (em forma de mingau) e o peixe de água doce, com frequência máxima de uma vez por semana. Em Florianópolis, a origem da culinária foi tipicamente açoriana - caracterizada pelo uso de peixes e frutos do mar -, sendo o camarão, o bolinho de bacalhau, mariscos, tainha assada e peixe pratos consumidos frequentemente ${ }^{27}$. No entanto, na alimentação escolar desse município, peixe ou mexilhão foram encontrados apenas uma vez por semana. Os dois exemplos demonstram a necessidade de maior conscientização da importância da introdução de alimentos regionais nos cardápios escolares como forma de promoção da identidade cultural do local e da maior aceitabilidade dos cardápios e facilidade de acesso aos locais.

Em Belém, a sazonalidade das frutas e o elevado valor dos produtos regionais, largamente exportados, contribuem para a limitação de seu uso na alimentação escolar. Foi relatado pelas entrevistadas que o açaí não é ofertado na alimentação escolar devido ao seu alto custo, ao seu risco microbiológico, uma vez que a procedência da água utilizada para a moagem algumas vezes é duvidosa, e ao fato de ser consumido com a utilização de muito açúcar refinado, o que o tornaria menos saudável.

Ainda cabe lembrar que, conforme dados da Pesquisa de Orçamentos Familiares 2008-200928, a aquisição de alimentos domiciliares per capita anual de hortaliças e frutas foi maior na região Sul $(39 \mathrm{~kg}$ e $37 \mathrm{~kg}$, respectivamente), enquanto a região Norte apresentou os menores valores (19kg e $21 \mathrm{~kg}$, respectivamente), ficando bem abaixo da média nacional $(27 \mathrm{~kg}$ e $29 \mathrm{~kg}$, respectivamente) ${ }^{28}$. Tais dados reforçam a importância da alimentação escolar, sobretudo na capital belenense.

Em 2004, a pedido do FNDE, o Instituto Nacional de Estudos e Pesquisas Educacionais Anísio Teixeira (INEP) inseriu, no questionário do censo escolar, um conjunto de questões sobre o PNAE. No item "preparação de cardápios", o estu- do observou algumas variações regionais: as frutas estavam mais presentes no Sul e Sudeste; carne enlatada no Norte; legumes e verduras no Sudeste e no Centro-Oeste; ovos no Sudeste, Centro-Oeste e Sul; salsichas no Sul e Sudeste; e carne/peixe/ frango com presença expressiva em todas as regiões, exceto Norte ${ }^{10}$.

A aquisição de gêneros alimentícios da agricultura familiar local se mostrou ainda restrita nas capitais. Um fator que interfere tanto na limitação da compra de alimentos por produtores locais quanto na inclusão de alimentos regionais na alimentação escolar é a concorrência "desleal" presente na licitação de compras. Em ambas as capitais, as entrevistadas relataram grande dificuldade de compras de produtores locais, tendo sido alegado que eles não apresentavam estrutura necessária para entregar os alimentos nas escolas, além de não produzirem a quantidade exigida no edital de licitação e não conseguirem oferecer produtos com custos competidores. Dessa forma, grandes produtores, oriundos de outros estados, acabavam muitas vezes selecionados para o fornecimento local.

O PNAE destaca a importância da agricultura familiar no fornecimento de gêneros alimentícios, no entanto ainda não dispõe de mecanismos precisos e suficientes para a inclusão desse grupo nos processos de compra. O Programa de Aquisição de Alimentos (PAA) é uma iniciativa do governo federal para incentivar a agricultura familiar e viabilizar a utilização dos seus produtos em escolas, creches, hospitais e outros projetos das prefeituras. A divulgação do PAA entre os promotores da agricultura familiar e da agroecologia visa a difundir estratégias que possam ajudar o desenvolvimento rural local e sustentáve|29,30.

\section{CONCLUSÃO}

O planejamento dos cardápios mostrou-se bem distinto nas duas capitais, refletindo a diversidade na execução do PNAE após a municipalização. Embora muitos pontos positivos tenham sido encontrados, sobretudo na capital 
catarinense, o estudo verificou que a frequência de alimentos regionais nos cardápios mostrou-se ainda tímida, com ausência de compra direta de agricultores familiares locais.

Tendo em vista que as políticas públicas que possuem como eixo norteador a Segurança Alimentar, como o PNAE, propõem um modelo de produção e consumo de alimentos mais sustentáveis, é preciso que sejam efetivamente institucionalizados instrumentos legais que possibilitem de forma abrangente a entrada dos pequenos produtores familiares no mercado, assim como se requer que as esferas governamentais se comprometam com o enfoque de direito de cidadania dos escolares atendidos pelo programa.

Diante dos importantes achados deste estudo, atenta-se para o fato de que a falta de uma avaliação sistemática da alimentação escolar nas capitais investigadas é um fator limitante para identificar alternativas de reestruturação do papel dos tomadores de decisão do Programa.

\section{COLABORADORES}

CG GABRIEL e LCF COSTA responsáveis pela concepção da pesquisa, coleta, análise e interpretação dos dados e redação do manuscrito. MCM CALVO e FAG VASCONCELOS responsáveis pela concepção da pesquisa, estruturação e revisão crítica do manuscrito.

\section{REFERÊ N CIAS}

1. Brasil. Ministério da Educação. Fundo Nacional de Desenvolvimento da Educação [Internet]. Alimentação Escolar. Brasilia; 2009 [acesso 2011 jan 13]. Disponível em: <http://www.fnde.gov.br/index. php/programas-alimentacao-escolar>.

2. Belik W, Chaim NA. O programa nacional de alimentação escolar e a gestão municipal: eficiência administrativa, controle social e desenvolvimento local. Rev Nutr. 2009; 22(5):595-607. doi: 10.1590/ S1415-52732009000500001.

3. Sturion GL, Silva MV, Ometto AMH, Furtuoso COM, Pipitone MAP. Fatores condicionantes da adesão dos alunos ao Programa de Alimentação Escolar no Brasil. Rev Nutr. 2005; 18(2):167-81. doi: 10.15 90/S1415-52732005000200001.
4. Spinelli MAS, Canesqui AM. Descentralização do Programa de Alimentação Escolar em Cuiabá: 1993-1996. Rev Nutr. 2004; 17(2):151-65. doi: 10.1590/S1415-52732004000200002.

5. Brasil. Lei $n^{\circ} 11.947$ de 16 de junho de 2009 . Dispõe sobre o atendimento da alimentação escolar e do Programa Dinheiro Direto na Escola aos alunos da educação básica; altera as Leis n 10.880 , de 9 de junho de 2004, 11.273, de 6 de fevereiro de 2006, 11.507, de 20 de julho de 2007; revoga dispositivos da Medida Provisória $n^{\circ} 2.178-36$, de 24 de agosto de 2001, e a Lei $n^{\circ} 8.913$, de 12 de julho de 1994; e dá outras providências. Diário Oficial da União. 2009 jun 17; p.2, Seção 1.

6. Brasil. Ministério da Educação. Fundo Nacional de Desenvolvimento da Educação. Resolução/CD/ FNDE $n^{\circ}$ 38, de 16 de julho de 2009 [acesso 2011 fev 1]. Disponível em: <ftp://ftp.fnde.gov.br/web/ resolucoes_2009/ res038_16072009.pdf>.

7. Santos LMP, Santos SMC, Santana LAA, Henrique FCS, Mazza RPD, Santos LAS, et al. Avaliação de políticas públicas de segurança alimentar e combate à fome no período 1995-2002. Programa Nacional de Alimentação Escolar. Cad Saúde Pública. 2007; 23(11):2681-93. doi: 10.1590/S0102-3 11X2007001100016.

8. Brasil. Conselho Federal de Nutricionistas. Resolução CFN n 465, de 23 de agosto de 2010 [acesso 2011 mar 13]. Disponível em: <http://www.cfn.org. br/novosite/arquivos/Resol-CFN-465-atribuicaonutricionista-AE.pdf>.

9. Gabriel CG, Santos MV, Vasconcelos FAG. Avaliação de um programa para promoção de hábitos alimentares saudáveis em escolares de Florianópolis, Santa Catarina, Brasil. Rev Bras. Saúde Matern Infant. 2008; 8(3):299-308. doi: 10.1590/S151938292008000300009 .

10. Instituto Nacional de Estudos e Pesquisas Educacionais Anísio Teixeira. Avaliação do Programa Nacional de Alimentação Escolar: censo escolar 2004 [Relatório Técnico]. Brasília: INEP; 2007 [acesso 2011 mar 4]. Disponível em: <http:// download.inep.gov.br/download/estudos pesquisas/financ_gasto/pnae_relatorio2004_ final.pdf $>$.

11. Brasil. Ministério da Saúde. Secretaria de Atenção à Saúde. Guia alimentar para a população brasileira: promovendo a alimentação saudável. Brasília: MS; 2006.

12. Chaves LG, Mendes PNR, Brito RR, Botelho RBA. O Programa Nacional de Alimentação Escolar como promotor de hábitos alimentares regionais. Rev Nutr. 2009; 22(6):857-66. doi: 10.1590/S1415-52 732009000600007.

13. Brasil. Ministério da Saúde. Portaria interministerial $n^{\circ} 1.010$, de 8 de maio de 2006. Institui as diretrizes 
promoção da alimentação saudável nas escolas de educação infantil, fundamental e nível médio das redes públicas e privadas, em âmbito nacional. Diário Oficial da União. 20069 maio.

14. Vianna RPT, Tereso MJA. O programa de merenda escolar de Campinas: análise do alcance e limitações do abastecimento regional. Rev Nutr. 2000; 13(1):41-9. doi: 10.1590/S1415-527320000001 00006.

15. Carvalho AT, Muniz VM, Gomes JF, Samico I. Programa de alimentação escolar no município de João Pessoa - PB. Brasil: as merendeiras em foco. Interface: Comunic Saúde Educ. 2008; 12(27): 823-34. doi: 10.1590/S1414-32832008000400 012.

16. Cunha E, Sousa AA, Machado NMV. A alimentação orgânica e as ações educativas na escola: diagnóstico para a educação em saúde e nutrição. Ciênc Saúde Coletiva. 2010; 15(1):39-49. doi: 10.1590/S1 413-81232010000100009.

17. Domene SMA, Pereira TC, Arrivillaga RK. Estimativa da disponibilidade de zinco em refeições com preparações padronizadas da alimentação escolar do município de Campinas. Rev Nutr. 2008; 21(2): 161-7. doi: 10.1590/S1415-52732008000200004.

18. Brasil. Ministério da Saúde. Secretaria de Políticas de Saúde. Alimentos regionais brasileiros. Brasília: MS; 2002.

19. Aguiar JPL. Tabela de composição alimentos da Amazônia. Acta Amaz. 1996; 26(1/2):121-6.

20. Instituto Nacional de Estudos e Pesquisas Educacionais Anísio Teixeira. Censo Escolar. 2010. [acesso 2011 abr 22]. Disponível em: <http://portal.inep. gov.br/basica-censo>

21. Instituto Brasileiro de Geografia e Estatística. Censo Demográfico 2010. [acesso 2011 mar 10]. Disponível em: <http://www.ibge.gov.br/home/ estatistica/populacao/censo2010/default_uf. shtm>.

22. Programa das Nações Unidas para o Desenvolvimento. Índice de Desenvolvimento Humano - Municipal: 1991 e 2000. [acesso 2011 jan 28]. Disponível em: <http://www.pnud.org.br>.
23. Instituto Brasileiro de Geografia e Estatística. Cidades. [acesso 2011 abr 13]. Disponível em: $<$ http://www.ibge.gov.br/cidadesat/topwindow. htm?1>.

24. Índice de Desenvolvimento da Educação Básica. Resultados e Metas. 2009. [acesso 2010 dez 13]. Disponível em: <http://sistemasideb.inep. gov.br/ resultado/>.

25. Flávio EF, Barcelos MFP, Cirillo MA, Ribeiro AH. Avaliação da alimentação escolar oferecida aos alunos do ensino fundamental das escolas municipais de Lavras, MG. Ciênc Agrotec. 2008; 32(6): 1879-87. doi: 10.1590/\$1413-70542008000600 029.

26. Vasconcelos FAG. Josué de Castro e a geografia da fome no Brasil. Cad Saúde Pública. 2008; 24(11):2710-7. doi: 10.1590/S0102-311X200800 1100027

27. Fisberg M, Wehba J, Cozzolino SMF. Um, dois, feijão com arroz: a alimentação no Brasil de norte a sul. São Paulo: Atheneu; 2002.

28. Instituto Brasileiro de Geografia e Estatística. Pesquisa de Orçamentos Familiares: 2008-2009. Aquisição alimentar domiciliar per capita anual, por grandes regiões, segundo os produtos: período 2008-2009. [acesso 2011 jan 13]. Disponível em: <http://www.ibge.gov.br/home/estatistica/ populacao/ condicaodevida/pof/2008_2009_ aquisicao/tabelas_pdf/tab111.pdf>.

29. Triches RM, Schneider S. Alimentação escolar e agricultura familiar: reconectando o consumo à produção. Saúde Soc. 2010; 19(4):933-45. doi: 10.1590/S0104-12902010000400019.

30. Conselho Nacional de Segurança Alimentar e Nutricional. Princípios e diretrizes de uma política de segurança alimentar e nutricional: textos de referência da II Conferência de Segurança Alimentar e Nutricional [acesso 2011 jan 22]. Disponível em: <http://www. planalto.gov.br/consea/static/ documentos/Outros/LivroConsea_Documento Referencia.pdf>.
Recebido em: 10/5/2011 Versão final em: 20/3/2012 Aprovado em: 8/5/2012 